\title{
Molecular heterogeneity of TFE3 activation in renal cell carcinomas
}

\author{
Stephan Macher-Goeppinger ${ }^{1,2}$, Wilfried Roth ${ }^{1,2}$, Nina Wagener ${ }^{3}$, Markus Hohenfellner ${ }^{3}$, \\ Roland Penzel ${ }^{1}$, Axel Haferkamp ${ }^{4}$, Peter Schirmacher ${ }^{1}$ and Sebastian Aulmann ${ }^{1}$ \\ ${ }^{1}$ Institute of Pathology, University of Heidelberg, Heidelberg, Germany; ${ }^{2}$ Clinical Cooperation Unit Molecular \\ Tumor Pathology, German Cancer Research Center, Heidelberg, Germany; ${ }^{3}$ Department of Urology, University \\ of Heidelberg, Heidelberg, Germany and ${ }^{4}$ Department of Urology, University of Frankfurt, Frankfurt, Germany
}

\begin{abstract}
Renal cell carcinomas associated with Xp11.2 translocations have recently been identified as a distinct biological entity. The translocation results in the fusion of the transcription factor TFE 3 to one of several different fusion partners including PRCC, PSF, NONO, ASPL or CTLC with consecutive overexpression of the chimeric protein. As the true frequency of these neoplasms as well as the biological properties of TFE3 activation in renal cell carcinomas are largely unknown, we have examined TFE3 expression as well as the underlying genetic alterations in a large, hospital-based series of renal cell carcinomas with long-term follow-up information. Out of a total of 876 tumours, TFE3 translocations were detected in five cases $(0.6 \%)$. Three additional cases were identified in a second series of cases comprising of renal cell carcinomas developing in patients before the age of $\mathbf{5 0}$. However, using immunohistochemistry, $9 \%$ of all renal cell carcinomas showed some degree of TFE3 reactivity. Interestingly, these cases were associated with high nuclear grade, greater tumour extent and metastatic disease as well as an unfavourable patient outcome on uni- and multivariate analysis. Fluorescence in situ hybridisation (FISH) revealed TFE3 amplifications as an additional, novel mechanism leading to increased TFE3 expression levels. In conclusion, our data show that Xp11 translocation renal cell carcinomas are uncommon tumours accounting for $<1 \%$ of adult renal cell carcinomas and that the diagnosis of Xp11 translocation renal cell carcinomas needs to be verified using molecular techniques. In turn, TFE3 overexpressing tumours show an aggressive behaviour and Xp11 translocation is only one of several possible underlying genomic alterations.

Modern Pathology (2012) 25, 308-315; doi:10.1038/modpathol.2011.169; published online 28 October 2011
\end{abstract}

Keywords: FISH; kidney; prognosis; renal cell carcinoma; TFE3; Xp11

Renal cell carcinomas associated with Xp11.2 translocations have recently been identified as a biologically distinct entity with characteristic clinical and morphological features. ${ }^{1}$ Although these tumours are uncommon in adult patients, they have been shown to comprise $\sim 30 \%$ of paediatric renal cell carcinomas. ${ }^{2}$ At present, five different translocations involving the Xp11.2 chromosomal region have been characterised, resulting in the fusion of the TFE3 (transcription factor binding to IGHM enhancer 3$)$ to PRCC (t(X;1)(p11;q21)), PSF (t(X;1) (p11;p34)), NONO (inv(X)(p11;q12)), ASPL $(\mathrm{t}(\mathrm{X} ; 17)(\mathrm{p} 11 ; \mathrm{q} 25))$ or $\operatorname{CLTC}(\mathrm{t}(\mathrm{X} ; 17)(\mathrm{p} 11 ; \mathrm{q} 23)) .{ }^{3-6} \mathrm{In}$

Correspondence: Dr S Macher-Goeppinger, MD, Institute of Pathology, University Hospital Heidelberg, Im Neuenheimer Feld 220/221, Heidelberg 69120, Germany.

E-mail: stephan.goeppinger@med.uni-heidelberg.de

Received 18 May 2011; revised 14 September 2011; accepted 14 September 2011; published online 28 October 2011 addition, another, at present unknown fusion partner of the TFE3 has recently been located on chromosome 19q13.1.7

TFE3 belongs to the microphthalmia transcription factor/transcription factor E (MITF-TFE) family, which in addition to microphthalmia-associated transcription factor (MITF) and TFE3 also includes TFEB and TFEC. Under physiological circumstances, MITF is a key regulator in melanocyte development. Gain of function of these genes has been associated with different tumour entities such as malignant melanomas, clear cell sarcoma and renal cell carcinomas. ${ }^{8,9}$ In addition to renal cell carcinomas, translocations of TFE3 have also been identified in alveolar soft part sarcoma and a subset of perivascular epithelioid cell neoplasms (PEComas). ${ }^{10,11}$

The biological behaviour of Xp11 translocation renal cell carcinomas has recently been documented in children and young adults, poor clinical outcome 
and early metastasis have been reported. ${ }^{12-14}$ To systematically assess the clinical and molecular properties of these tumours, we have examined TFE3 expression as well as the underlying genetic alterations in a large, hospital-based series of renal cell carcinomas with long-term follow-up information.

\section{Patients and methods}

\section{Patients}

Tissue samples from 932 patients with primary renal cell carcinomas treated at the Department of Urology at the University of Heidelberg between 1987 and 2005 were collected. The human tissue samples were provided by the Tumour Tissue Bank of the National Centre for Tumour Diseases Heidelberg after approval by the Ethics Committee of the University of Heidelberg. No adjuvant treatment of localised disease was administered. Patients with metastases, a Karnofsky performance index of $\geq 80$ and no medical contraindications received palliative interferon- $\alpha$ - and IL-2-based immunotherapy. No targeted therapeutic approaches were performed. Clinical follow-up was available for 911 cases. All tissue samples were reviewed by experienced pathologists. Tumour classification and grading were performed according to the World Health Organisation, for staging, the 7th edition of the TNM classification (TNM 2009) was used. ${ }^{1}$

\section{Tissue-Micro-Arrays}

A series of tissue microarrays containing 932 primary tumour and corresponding normal tissue samples of the 932 patients were created as described previously. ${ }^{15,16}$ In total, a set of 19 array blocks was generated, each containing 200 tissue core specimens, representing 50 patients per array. A second TMA containing 104 cases of renal cell carcinomas that had developed in patients before the age of 50 was created. A morphologically representative region was chosen from each of the renal cell carcinomas and two cylindrical core tissue specimens per tumour block measuring $1 \mathrm{~mm}$ in diameter were punched from these regions and arrayed into the recipient paraffin block. Of these 104 cases, 57 had already been included in the original arrays described above whereas 47 cases represented new tumours.

\section{Immunohistochemistry}

Tissue microarray slides were stained with a polyclonal anti-TFE3 antiserum (final concentration $2 \mu \mathrm{g} / \mathrm{ml}$; P-16, Santa Cruz Biotechnology, Heidelberg, Germany) as described previously. ${ }^{17}$ Nuclear staining intensity was assessed using a three-tiered scoring system. In addition, the absence or presence of cytoplasmic TFE3 expression was noted.
The arrays were independently scored by two experienced pathologists (SMG, SA) blinded to tissue annotations and patient outcomes.

\section{Fluorescence In Situ Hybridization (FISH)}

The generation of DNA probes flanking the TFE3 locus (chromosome Xp11.2), a third probe centromeric of $A S P L$ gene (chromosome 17q25.3) and FISH analysis of TFE3 has previously been described in detail. ${ }^{17}$ In addition, a commercially available DNA-probe labelling the centromer $X$ (MP Biomedicals Europe, Illkirch, France) was used to assess chromosome $\mathrm{X}$ aneuploidy.

\section{Reverse Transcription PCR and Sequence Analyses}

RNA extraction and RT-PCR was performed as described previously. ${ }^{17}$ Fusion transcripts were detected with the primer combinations summarised in Table 1 followed by direct DNA sequencing using the DYEnamic ET terminator sequencing kit (GE Healthcare) on an ABI prism 377 sequencer (Applied Biosystems, Darmstadt, Germany).

\section{Statistical Methods}

Data were analysed using the $\mathrm{R}$ software package (version 2.5.1, http://www.rproject.org). For count data, Fisher's exact test (two-sided) was used. The Kaplan-Meier method was applied to calculate

Table 1 Primer pairs used for RT-PCR

\begin{tabular}{|c|c|}
\hline $\mathrm{t}(\mathrm{X} ; 17)(\mathrm{p} 11 ; \mathrm{q} 25)$ & 5'-AAAGAAGTCCAAGTCGGGCCA-3' \\
\hline \multirow[t]{2}{*}{ ASPL-TFE3 type1 } & ASPL exon 7 \\
\hline & $\begin{array}{l}5^{\prime} \text {-CATCAAGCAGATTCCCTGACACA-3' } \\
\text { TFE } 3 \text { exon } 5\end{array}$ \\
\hline $\mathrm{t}(\mathrm{X} ; 17)(\mathrm{p} 11 ; \mathrm{q} 25)$ & 5'-AAAGAAGTCCAAGTCGGGCCA-3' \\
\hline \multirow[t]{2}{*}{ ASPL-TFE3 type2 } & ASPL exon 7 \\
\hline & $\begin{array}{l}5^{\prime} \text {-TGGACTCCAGGCTGATGATCTC-3' } \\
\text { TFE3 exon } 6\end{array}$ \\
\hline $\mathrm{t}(\mathrm{X} ; 17)(\mathrm{p} 11 ; \mathrm{q} 23)$ & 5'-GAGATCCACATCTGGCCTGT-3' \\
\hline \multirow[t]{2}{*}{ CLTC-TFE3 } & CLTC exon 17 \\
\hline & $\begin{array}{l}5^{\prime} \text {-TGGACTCCAGGCTGATGATCTC-3' } \\
\text { TFE3 exon } 6\end{array}$ \\
\hline $\operatorname{inv}(X)(p 11 ; q 12)$ & $5^{\prime}$-CGGCAGCAAGAAGAAATGAT-3' \\
\hline \multirow[t]{2}{*}{ NONO-TFE3 } & NONO exon 9 \\
\hline & 5'-GCAGGAGTTGCTGACAGTGA-3' \\
\hline $\mathrm{t}(\mathrm{X} ; 1)(\mathrm{p} 11 ; \mathrm{p} 34)$ & $\begin{array}{l}\text { TFE3 exon } 6 \\
5^{\prime} \text {-TGAAGCTAATCCTGGCGTTC-3' }\end{array}$ \\
\hline \multirow[t]{2}{*}{ PSF-TFE3 } & PSF exon 9 \\
\hline & $\begin{array}{l}5^{\prime} \text {-TGGACTCCAGGCTGATGATCTC-3' } \\
\text { TFE3 exon } 6\end{array}$ \\
\hline $\mathrm{t}(\mathrm{X} ; 1)(\mathrm{p} 11 ; \mathrm{q} 21)$ & 5'-TGGTGGCTACTATCCTGCAC-3' \\
\hline \multirow[t]{2}{*}{ PRCC-TFE3 type1 } & PRCC exon 4 \\
\hline & $\begin{array}{l}5^{\prime} \text {-CGAGTGTGGTGGACAGGTACT-3' } \\
\text { TFE3 exon } 4\end{array}$ \\
\hline $\mathrm{t}(\mathrm{X} ; 1)(\mathrm{p} 11 ; \mathrm{q} 21)$ & $5^{\prime}$-CCAAGCCAAAGAAGAGGAAA- ${ }^{\prime}$ \\
\hline \multirow[t]{2}{*}{ PRCC-TFE3 type2 } & PRCC exon 1 \\
\hline & $\begin{array}{l}5^{\prime} \text {-CGAGTGTGGTGGACAGGTACT-3' } \\
\text { TFE3 exon } 4\end{array}$ \\
\hline
\end{tabular}


survival probabilities for both progression-free and cancer-specific overall survival. For multivariate analysis, the Cox proportional hazards regression model was used. Univariate survival data were tested for significance using the Mantel-Haenszel $\log$ rank test. $P$-values $<0.05$ were considered significant.

\section{Results}

\section{TFE3 Immunohistochemistry}

TFE3 immunostains were performed on tissue microarrays containing tumour and corresponding normal renal tissue from 932 patients with renal cell carcinomas. A total of 56 cases were excluded from further analyses either because of insufficient tumour tissue, poor tissue preservation or missing patient information. The clinical and pathological features of the remaining 876 cases are summarised in Table 2. Median follow-up time was 59 months (mean, 62 months). TFE3 expression was detected in a total of 76 cases $(9 \%)$. Of these, 26 tumours $(3 \%)$ showed weak, another $26(3 \%)$ moderate $10(1 \%)$ strong nuclear staining. Cytoplasmic TFE3 staining was detected in 14 tumours (2\%), the remaining 800 cases $(91 \%)$ were completely negative.

\section{TFE3 FISH Analysis and RT-PCR}

Tissue for FISH analysis was available in 50 (76\%) cases with either nuclear or cytoplasmic TFE3 staining including 9 of the 10 tumours with strong nuclear TFE3 expression. Translocations of TFE3 were found in four cases showing strong nuclear, and one case with cytoplasmatic TFE3 expression, the remaining 45 cases including five tumours with strong nuclear TFE3 reaction did not harbour a TFE3 translocation (Figure 1). To identify the underlying translocation RT-PCR was performed. PCR results and the clinicopathologic characteristics of the five patients with a Xp11 translocation renal cell carcinoma are summarised in Table 3.

\section{Validation of TFE3 Immunohistochemistry Results}

To investigate the frequency of immunhistochemically TFE3 negative Xp11 translocation renal cell carcinomas we constructed a second TMA containing 104 cases of renal cell carcinomas that had developed in patients before the age of 50 as renal cell carcinomas associated with Xp11. 2 translocations have been reported to frequently occur in younger patients. ${ }^{18}$ Of these 104 cases (median age at surgery: 39 years, range 4-50 years), 57 had already been included in the original arrays described above whereas 47 cases represented new tumours for which no follow-up information was available. TFE3-FISH analysis was performed on the whole subset, confirming translocations in five
Table 2 Clinicopathological characteristics of the study population

\begin{tabular}{|c|c|}
\hline Variable & $\mathrm{n}(\%)$ \\
\hline Study population & 876 \\
\hline \multicolumn{2}{|l|}{ Sex } \\
\hline Female & $331(38)$ \\
\hline Male & $545(62)$ \\
\hline \multicolumn{2}{|c|}{ Age at surgery, years (median 63; range 14-89) } \\
\hline$<65$ & $493(56)$ \\
\hline$>65$ & $383(44)$ \\
\hline \multicolumn{2}{|c|}{ Karnofsky severity rating, \% } \\
\hline$\geq 80$ & $808(92)$ \\
\hline$<80$ & $68(8)$ \\
\hline \multicolumn{2}{|l|}{ Tumour extent } \\
\hline Stage 1 & $477(54)$ \\
\hline Stage 2 & $93(11)$ \\
\hline Stage 3 & $281(32)$ \\
\hline Stage 4 & $25(3)$ \\
\hline \multicolumn{2}{|l|}{ Fuhrman grade } \\
\hline G1 & $221(25)$ \\
\hline G2 & $502(57)$ \\
\hline G3 & $143(16)$ \\
\hline G4 & $4(<1)$ \\
\hline Not classified & $6(<1)$ \\
\hline \multicolumn{2}{|l|}{ Distant metastasis } \\
\hline Yes & $141(16)$ \\
\hline No & $735(84)$ \\
\hline \multicolumn{2}{|c|}{ Lymphnode metastasis } \\
\hline Yes & $68(8)$ \\
\hline No & $808(92)$ \\
\hline \multicolumn{2}{|c|}{ Histopathological subtype } \\
\hline Clear cell & $736(84)$ \\
\hline Papillary & $88(10)$ \\
\hline Chromophobe & $31(4)$ \\
\hline Collecting duct & $3(<1)$ \\
\hline Not classified & $18(1)$ \\
\hline
\end{tabular}

cases including two cases that had already been identified in the first series and three new Xp11 translocation renal cell carcinomas (Table 3). However, TFE3 immunohistochemistry positively labelled a total of 12 renal cell carcinomas, including the five cases with TFE3 translocations as detected by FISH and additional seven tumours without detectable alterations of the TFE3.

\section{TFE3 Amplification}

Besides translocation, some tumours showed amplification of TFE3 with between four and eight signals per nucleus (Figure 1). In all, 24\% of renal cell carcinomas with moderate to strong nuclear expression and no evidence of a TFE3 translocation displayed four or more hybridisation signals, compared with $8 \%$ of renal cell carcinomas showing no 

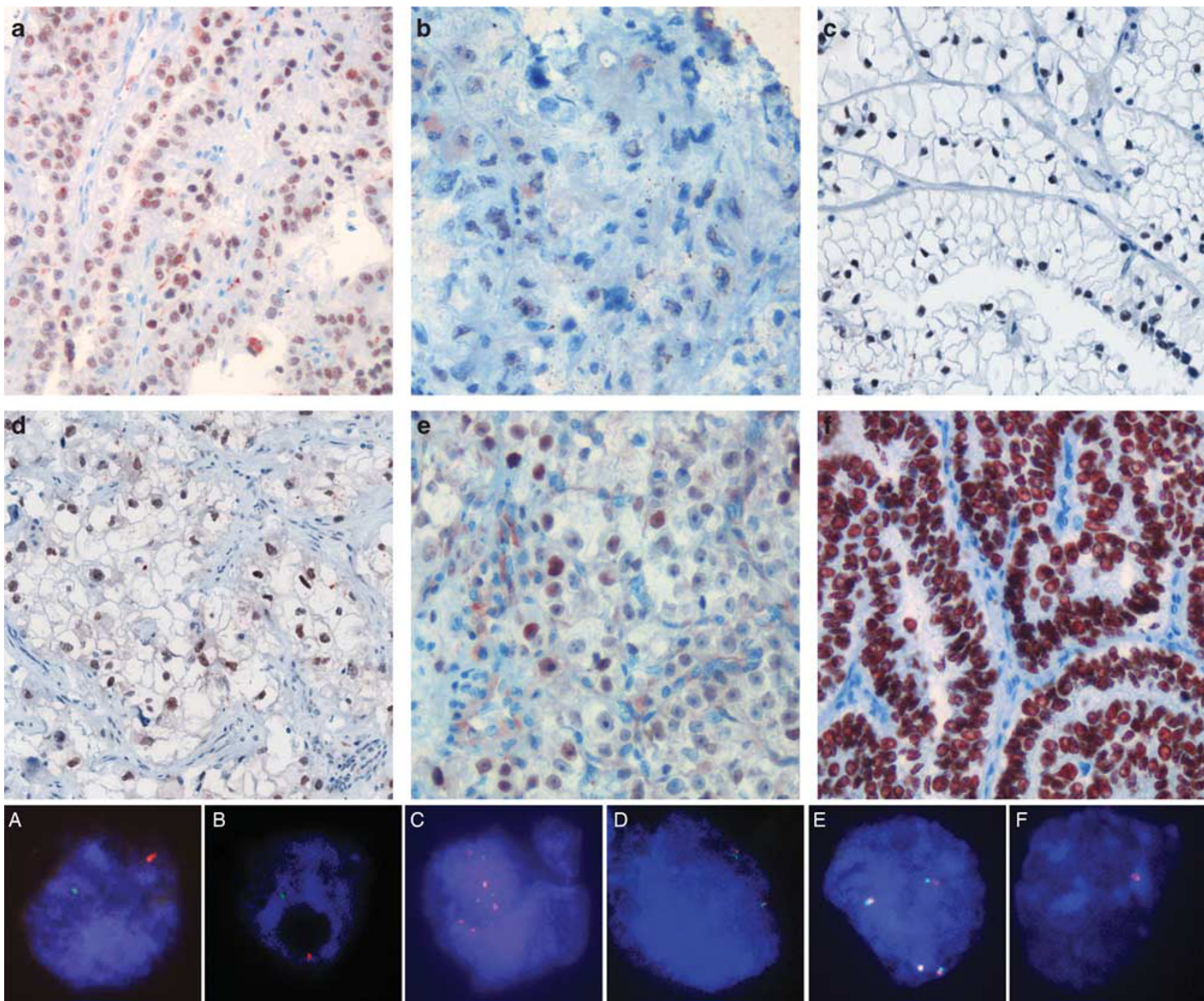

Figure 1 Immunohistochemical demonstration of TFE3 expression (a-f) and corresponding split fluorescence in situ hybridisation (FISH) with probes telomeric (Cy3) and centromeric (fluorescein isothiocyanate (FITC)) of TFE3 (a-f). (A-C) Demonstrate TFE3 rearrangements; (D-F) demonstrate normal combination red-green signals. Note the amplification in panels $\mathbf{C}$ and $\mathbf{E}$.

Table 3 Clinicopathological characteristics of patients with Xp11 translocation renal cell carcinomas ${ }^{\mathrm{a}}$

\begin{tabular}{|c|c|c|c|c|c|c|c|c|}
\hline & Patient 1 & Patient 2 & Patient 3 & Patient 4 & Patient 5 & Patient $6^{\mathrm{b}}$ & Patient $7^{\mathrm{b}}$ & Patient $8^{\mathrm{b}}$ \\
\hline Age at diagnosis (years) & 63 & 47 & 28 & 40 & 75 & 4 & 28 & 28 \\
\hline Sex & $\mathrm{F}$ & $\mathrm{F}$ & $\mathrm{F}$ & $\mathrm{F}$ & $\mathrm{F}$ & M & $\mathrm{F}$ & M \\
\hline Tumour extent & 3 & 1 & 3 & 1 & 1 & 3 & 4 & 3 \\
\hline Lymphnode metastasis & $\mathrm{Y}$ & 0 & $\mathrm{Y}$ & 0 & 0 & $\mathrm{Y}$ & $\mathrm{Y}$ & 0 \\
\hline Distant metastasis & Y (lung) & $\mathrm{N}$ & $\mathrm{N}$ & $\mathrm{N}$ & $\mathrm{N}$ & $\mathrm{N}$ & $\mathrm{N}$ & $\mathrm{N}$ \\
\hline Local recurrence & $\mathrm{N}$ & $\mathrm{N}$ & $\mathrm{Y}$ & $\mathrm{N}$ & $\mathrm{N}$ & $\mathrm{N}$ & NA & NA \\
\hline Metachronous metastasis & $\mathrm{N}$ & $\mathrm{N}$ & Y (lung) & $\mathrm{N}$ & $\mathrm{N}$ & $\mathrm{N}$ & NA & NA \\
\hline Observation period (months) & 12 & 117 & 20 & 93 & 125 & 129 & NA & NA \\
\hline Cancer specific death & $\mathrm{Y}$ & $\mathrm{N}$ & $\mathrm{Y}$ & $\mathrm{N}$ & $\mathrm{N}$ & $\mathrm{N}$ & NA & NA \\
\hline Immunohistochemistry $^{\mathrm{c}}$ & Strong & Strong & Strong & Cytoplasmic & Strong & Moderate & Strong & Weak \\
\hline TFE3-FISH & Split & Split & Split & Split & Split & Split & Split & Split \\
\hline RT-PCR & NA & NA & PRCC/TFE3 & NA & PSF/TFE3 & ASPL/TFE3 & PSF/TFE3 & NA \\
\hline
\end{tabular}

Abbreviations: N, no; NA, not applicable; Y, yes.

${ }^{\mathrm{a}}$ All identified Xp11 translocation renal cell carcinomas including both TMAs.

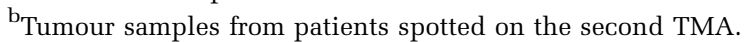

${ }^{\mathrm{C}}$ Nuclear, if not otherwise specified. 
nuclear TFE3 expression. Furthermore all four cases with six or more signals were immunohistochemically TFE3 positive (Table 4). Aneuploidy for $\mathrm{X}$-chromosome was detected in four cases with increased TFE3 copy numbers (between four and six signals per nucleus).

Table 4 Comparison of TFE3 expression and and FISH results

Number of cases grouped by TFE3 expression

FISH signals Negative Weak Moderate Strong Cytoplasmic

\begin{tabular}{rrrrrr}
\hline 1 & 35 & 6 & 8 & 2 & 4 \\
2 & 30 & 5 & 7 & 2 & 3 \\
3 & 1 & 3 & 0 & 0 & 0 \\
4 & 3 & 0 & 2 & 0 & 1 \\
5 & 3 & 0 & 0 & 1 & 0 \\
6 & 0 & 0 & 2 & 0 & 0 \\
7 & 0 & 0 & 1 & 0 & 0 \\
8 & 0 & 1 & 0 & 0 & 0 \\
\hline
\end{tabular}
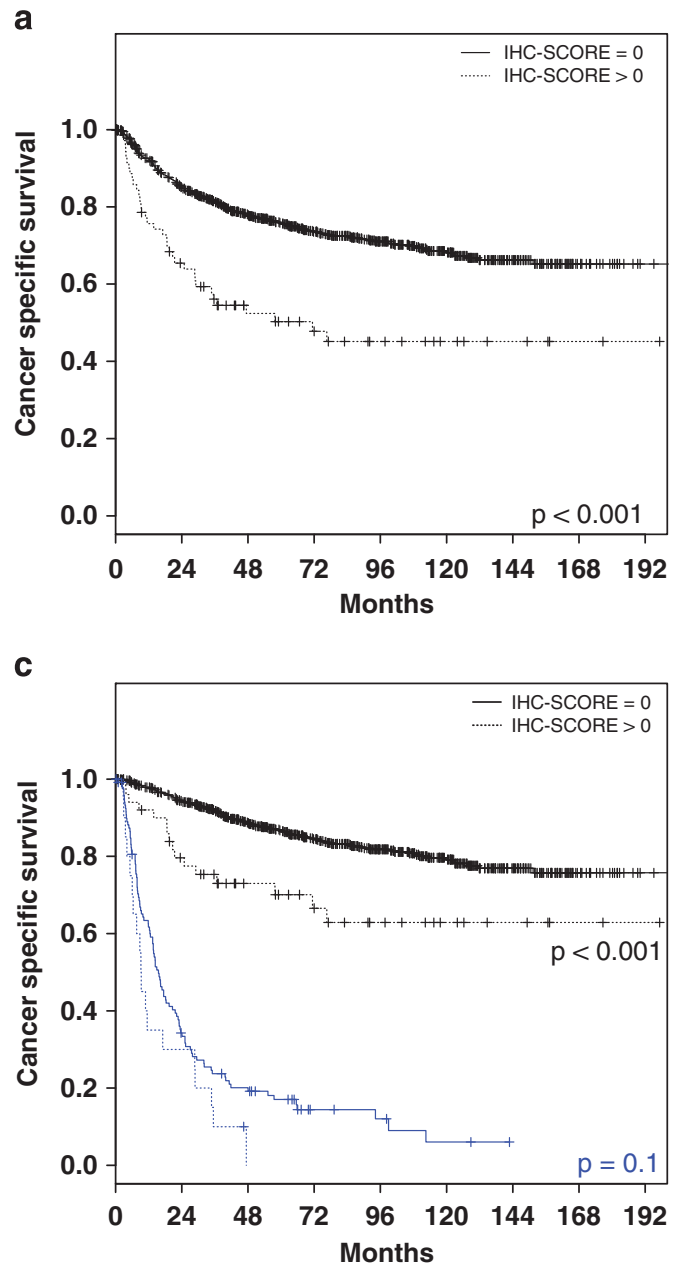

Comparison of TFE3 Expression Levels in Non-Xp11 Renal Cell Carcinomas with Clinical and Pathological Features

Univariate analyses showed a significantly poorer cancer-specific survival for tumours with TFE3 expression $(P<0.001)$. This applies for the subset with amplification $(P<0.001)$ and for the subset with unknown underlying pathomechanisms for TFE3 overexpression/expression $(P<0.001)$. For the five adult patients with Xp11 translocation renal cell carcinomas univariate survival analyses did not reach statistical significance possibly because of the low number of patients (Figure 2). In tumours without TFE3 translocations, nuclear or cytoplasmic TFE3 expression was strongly associated with grade of malignancy, tumour extent as well as distant and regional lymph node metastasis (Table 5).

To further validate this finding, a multivariate analysis was performed using the Cox proportional hazards model (Table 6). The results confirm TFE3 expression as an independent unfavourable
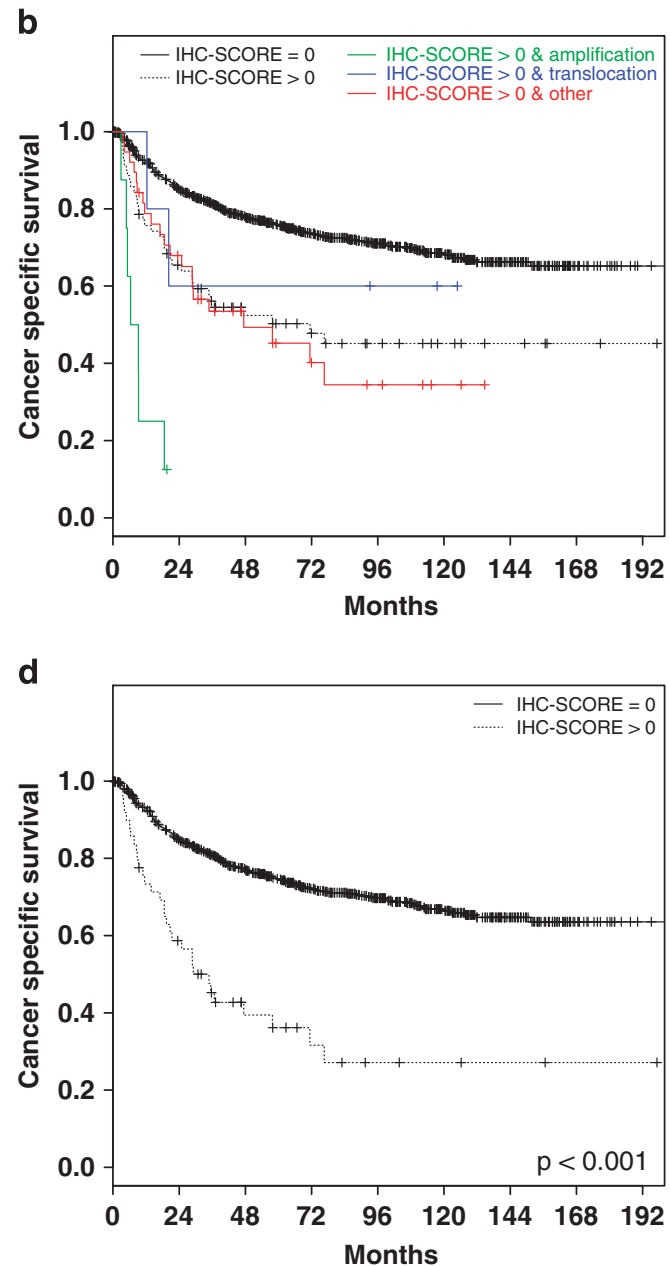

Figure 2 Analysis of cancer-specific survival depending on TFE3 expression levels. (a) All patients $(n=876)$. (b) Analysis of cancerspecific survival depending on TFE3 overexpression and underlying molecular pathomechanism. (c) Patients with non-metastatic disease (M0, $n=735)$ vs metastatic disease (M1, $n=141$ ). (d) Patients with clear cell renal cell carcinomas $(n=736)$. 
prognostic marker in the whole collective $(P<0.001)$ as well as in patients with clear cell renal cell carcinomas $(P<0.001)$ and clear cell renal cell carcinomas without metastases at the time of diagnosis $(P=0.037)$ (Table 7$)$.

Table 5 Correlation of TFE3 expression in non-Xp11 renal cell carcinomas with clinicopathological characteristics

\begin{tabular}{|c|c|c|c|}
\hline Variable & $\begin{array}{c}\text { TFE3 positive, } \\
\text { n (\%) }\end{array}$ & $\begin{array}{c}\text { TFE3 negative, } \\
\mathrm{n}(\%)\end{array}$ & $\mathrm{P}$ \\
\hline \multicolumn{3}{|l|}{ Sex } & \multirow[t]{3}{*}{0.966} \\
\hline Female & $20(29)$ & $306(38)$ & \\
\hline Male & $51(71)$ & $494(62)$ & \\
\hline \multicolumn{3}{|c|}{ Age at surgery, years } & \multirow[t]{3}{*}{0.061} \\
\hline$<65$ & $32(46)$ & 457 (57) & \\
\hline$>65$ & $39(54)$ & $343(43)$ & \\
\hline \multicolumn{3}{|c|}{ Karnofsky severity rating \% } & \multirow[t]{3}{*}{0.108} \\
\hline$\geq 80$ & $62(87)$ & 742 (93) & \\
\hline$<80$ & $9(13)$ & $58(7)$ & \\
\hline \multicolumn{3}{|l|}{ Tumour extent } & \multirow[t]{3}{*}{0.003} \\
\hline Stage $1 / 2$ & $34(47)$ & $533(67)$ & \\
\hline Stage $3 / 4$ & $37(53)$ & $267(33)$ & \\
\hline \multicolumn{3}{|l|}{ Fuhrman grade } & \multirow[t]{3}{*}{$<\mathbf{0 . 0 0 1}$} \\
\hline $\mathrm{G} 1 / 2$ & $46(64)$ & $673(85)$ & \\
\hline $\mathrm{G} 3 / 4$ & $25(36)$ & $121(15)$ & \\
\hline \multicolumn{3}{|c|}{ Distant metastasis } & \multirow[t]{3}{*}{0.007} \\
\hline No & $51(71)$ & $680(85)$ & \\
\hline Yes & $20(29)$ & $120(15)$ & \\
\hline \multicolumn{3}{|c|}{ Lymphnode metastasis } & \multirow[t]{3}{*}{0.108} \\
\hline No & $62(87)$ & 743 (93) & \\
\hline Yes & $9(13)$ & $57(7)$ & \\
\hline \multicolumn{3}{|c|}{ Histopathological subtype } & \multirow[t]{3}{*}{0.001} \\
\hline Clear cell & $49(69)$ & $682(85)$ & \\
\hline Other types & $22(31)$ & $118(15)$ & \\
\hline
\end{tabular}

Bold values are significant at $P<0.05$.

\section{Discussion}

Contrasting conventional renal cell carcinomas, Xp11.2 translocation associated tumours are not defined on a morphological but solely on a genetic basis. Initially described in children and designated as 'juvenile papillary renal cell carcinoma', there today is increasing evidence that these uncommon neoplasms also occur in adults although their true incidence and clinical peculiarities have not been evaluated in detail. ${ }^{18,19}$

To systematically analyse the role of TFE3 alterations in unselected renal cell carcinomas, we have combined TFE3 immunohistochemistry with molecular analyses of the underlying genomic alterations. In a series of 876 well-characterised renal cell carcinomas, immunohistochemistry revealed that the vast majority (91\%) of tumours showed no TFE3 expression at all, whereas the remaining 9\% exhibited varying cytoplasmic or nuclear staining patterns. Tissue samples of nine tumours with strong nuclear TFE3 expression, a criterion previously used as an indicator of TFE 3 translocations, were available for FISH analyses. ${ }^{18,20}$ Only four out of these nine tumours (44\%) harboured a TFE3 translocation. On the other hand, not only these four cases but also all other genetically verified Xp11 translocation renal cell carcinomas from the second TMA series of 104 younger renal cell carcinoma patients showed at least weak nuclear or cytoplasmic positivity. This suggests that immunohistochemistry is a highly sensitive method that may be used as an initial screening tool, but that the diagnosis of Xp11 translocation renal cell carcinomas needs to be genetically verified. As there is evidence of further, as yet unrecognised fusion variants, the direct visualisation of the TFE3 split

Table 6 Uni- and multivariate analyses of prognostic factors influencing CSS

\begin{tabular}{|c|c|c|c|c|}
\hline & \multicolumn{2}{|c|}{ Univariate analysis } & \multicolumn{2}{|c|}{ Multivariate analysis } \\
\hline & $H R(95 \% C I)$ & $\mathrm{P}$ & $H R(95 \% C I)$ & $\mathrm{P}$ \\
\hline Grade of malignancy ${ }^{\mathrm{a}}$ & $5.83(4.53-7.49)$ & $<\mathbf{0 . 0 0 1}$ & $2.18(1.642-2.90)$ & $<0.001$ \\
\hline Tumor extent ${ }^{\mathrm{b}}$ & $5.97(4.58-7.79)$ & $<\mathbf{0 . 0 0 1}$ & $2.885(2.127-3.91)$ & $<\mathbf{0 . 0 0 1}$ \\
\hline Distant metastasis ${ }^{\mathrm{c}}$ & $12.7(9.78-16.4)$ & $<\mathbf{0 . 0 0 1}$ & $6.962(5.179-9.36)$ & $<\mathbf{0 . 0 0 1}$ \\
\hline Regional lymph node metastasis ${ }^{\mathrm{d}}$ & $6.31(4.68-8.52)$ & $<\mathbf{0 . 0 0 1}$ & $1.306(0.929-1.84)$ & 0.1 \\
\hline Histopathologic subtype $\mathrm{e}^{\mathrm{e}}$ & $1.65(1.11-2.46)$ & 0.014 & $1.19(0.788-1.80)$ & 0.4 \\
\hline $\operatorname{Sex}^{\mathrm{f}}$ & $0.665(0.51-0.866)$ & 0.0025 & $0.767(0.583-1.01)$ & 0.06 \\
\hline Karnofsky performance status ${ }^{\mathrm{g}}$ & $2.08(1.41-3.07)$ & $<\mathbf{0 . 0 0 1}$ & $1.867(1.254-2.78)$ & ‘0.002 \\
\hline TFE3 expression ${ }^{\mathrm{h}}$ & $2.44(1.71-3.49)$ & $<\mathbf{0 . 0 0 1}$ & $1.849(1.288-2.66)$ & $<\mathbf{0 . 0 0 1}$ \\
\hline
\end{tabular}

${ }^{\mathrm{a}} \mathrm{G} 3 / \mathrm{G} 4$ vs G1/G2.

${ }_{\mathrm{p}} \mathrm{p} 3 / \mathrm{pT} 4$ vs $\mathrm{pT} 1 / \mathrm{pT} 2$.

${ }^{\mathrm{C}} \mathrm{M} 1$ vs M0.

$\mathrm{d}_{\mathrm{pN} 1 / \mathrm{pN} 2 \text { vs No/pNo. }}$

${ }^{\mathrm{e}}$ Clear cell (conventional) vs other types.

${ }^{\mathrm{f}}$ Female vs male.

g $<80 \%$ vs $\geq 80 \%$.

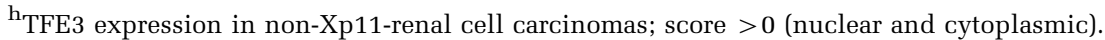

Bold values are significant at $P<0.05$. 
Table 7 Multivariate analyses of prognostic factors influencing CSS in clear cell renal cell carcinomas

\begin{tabular}{|c|c|c|c|c|}
\hline & \multicolumn{2}{|c|}{ Mo } & \multicolumn{2}{|c|}{ M1 } \\
\hline & $H R(95 \% C I)$ & $\mathrm{P}$ & $H R(95 \%$ CI $)$ & $P$ \\
\hline Grade of malignancy ${ }^{a}$ & $2.5(1.612-3.878)$ & $<\mathbf{0 . 0 0 1}$ & $1.764(1.174-2.65)$ & 0.0063 \\
\hline Tumor extent $\mathrm{t}^{\mathrm{b}}$ & $3.788(2.465-5.821)$ & $<0.001$ & $1.735(1.096-2.75)$ & 0.0190 \\
\hline Regional lymph node metastasis ${ }^{\mathrm{C}}$ & $2.687(1.566-4.610)$ & $<0.001$ & $0.906(0.546-1.50)$ & 0.7 \\
\hline Sex $^{\mathrm{d}}$ & $0.673(0.456-0.994)$ & 0.046 & $0.904(0.580-1.41)$ & 0.66 \\
\hline Karnofsky performance status ${ }^{\mathrm{e}}$ & $0.996(0.508-1.953)$ & 0.99 & $2.559(1.465-4.47)$ & $<\mathbf{0 . 0 0 1}$ \\
\hline TFE3 expression ${ }^{\mathrm{f}}$ & $1.852(1.037-3.308)$ & 0.037 & $1.740(0.999-3.03)$ & 0.05 \\
\hline
\end{tabular}

${ }^{\mathrm{a}} \mathrm{G} 3 / \mathrm{G} 4$ vs $\mathrm{G} 1 / \mathrm{G} 2$.

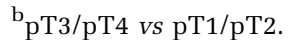

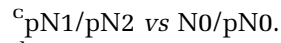

${ }^{\mathrm{d}}$ Female vs male.

${ }^{\mathrm{e}}<80 \%$ vs $\geq 80 \%$.

${ }^{\mathrm{f}}$ TFE3 expression in non-Xp11-renal cell carcinomas; score $>0$ (nuclear and cytoplasmic).

Bold values are significant at $P<0.05$.

remains the method with the highest sensitivity for paraffin-embedded, clinical tissue samples., ${ }^{7,17,21}$

Of the eight genetically verified Xp11 translocation renal cell carcinomas in both series, seven occurred in adult patients corresponding to an overall frequency of $0.75 \%$ Xp11-associated tumours in unselected (adult) cases. The average age of patients with Xp11 translocation renal cell carcinomas was 44 years, the oldest patient 75 years at diagnosis. Although some Xp11 translocation renal cell carcinomas already develop in paediatric patients, it appears that the entity in itself is a rare tumour that may occur at any age.

As TFE3 expression in renal cell carcinomas obviously is not limited to Xp11.2 translocations, we further sought to examine its biological properties in usual type renal cell carcinomas (carcinomas with no detectable Xp11 translocation). Nuclear and/or cytoplasmic TFE3 immunoreactivity was detected in a total of $71(9 \%)$ of the 876 tumours. Besides translocations, FISH demonstrated increased TFE3 copy numbers (four to eight signals/ per nucleus) based on gene amplification or aneuploidy in eight immunohistochemically positive tumours. This observation is in line with the previous report of a PEComa containing a TFE3 amplification. ${ }^{11}$ However, in 40 tumours neither amplifications nor translocations were detected, suggesting the presence of further genetic or epigenetic alterations leading to TFE3 overexpression. Recently, Hong et $a l^{22}$ reported TFE3 activation upon inactivation of the tumour suppressor gene FLCN (folliculin). Interestingly, FLCN germline mutations are the genetic background of Birt-HoggDube' syndrome, an uncommon disorder characterized by the development of noncancerous tumours of the hair follicles, lung cysts and renal cell carcinomas. In summary, these data point to the presence of different mechanisms (ie, TFE3 translocation, amplification and FLCN inactivation) that can result in increased TFE3 protein levels in renal cell carcinomas.
Interestingly, renal cell carcinomas with no detectable Xp11 translocation and increased TFE3 expression were significantly associated with unfavourable clinico-pathological features such as higher nuclear grade, advanced tumour stage and the presence of metastatic disease. Especially TFE3positive non-Xp11 renal cell carcinomas showed a substantially poorer disease-specific overall survival both on univariate and on multivariate analysis. Aggressive clinical behaviour of Xp11 translocation renal cell carcinomas has been reported in previous series and case reports. ${ }^{13}$ However, most of these data represent observations in preselected collectives of younger patients. In addition, TFE3-positive tumours without Xp11 translocations typically are not distinguished from true Xp11 translocation renal cell carcinomas. The different genetic alterations leading to TFE3 activation suggest a possible selection by function in renal cell carcinomas, a fact that is further supported by the substantially poorer patient outcome regardless of the underlying mechanism.

As oncogenic TFE3 fusion proteins have been shown to activate MET transcription in vitro, detection of increased TFE3 protein levels in up to $10 \%$ of renal cell carcinomas may define a subset of cases with an especially poor prognosis, for which novel MET inhibitors could be of therapeutic value. ${ }^{23,24}$ However, as response to MET inhibitors may depend on the pathomechanism of TFE3 activation, verification of Xp11 translocations could be of additional relevance in this clinical setting.

In conclusion, our data show that TFE3 activation is not limited to renal cell carcinomas associated with Xp11.2 translocations but may also be observed in a subset of usual type renal cell carcinomas characterised by an unfavourable clinical behaviour and poor patient survival. We could identify amplifications of the TFE3 as one novel underlying alteration in some of these cases. However, our findings also indicate that there are further, yet unknown molecular mechanisms leading to 
increased TFE3 protein levels in renal cell carcinomas. Importantly, the increasing molecular insight into the interactions of MIT family transcription factors, such as TFE3 and MET, may point towards a potential therapeutic use of MET inhibition in these uncommon tumours.

\section{Acknowledgement}

We thank Sandra Hahn, Kerstin Mühlburger, Bettina Walter and Andrea Hain for excellent technical assistance and Hildegard Jakobi for excellent help with the patient data. This work was supported by the Postdoc Fellowship from the University of Heidelberg to SMG, by a grant from the Deutsche Krebshilfe to WR (German Cancer Aid, Max Eder Program), and the Tissue Bank of the National Center for Tumor Diseases Heidelberg.

\section{Disclosure/conflict of interest}

The authors declare no conflict of interest.

\section{References}

1 Argani P, Ladanyi M. Renal carcinomas associated with Xp11.2 translocations/TFE3 gene fusions. In: Eble JN, Sauter G, Epstein J, et al., (eds). Pathology and Genetics of Tumors of the Urinary System \& Male Genital Organs. IARC: Lyon, France, 2004, pp 37-38.

2 Argani P, Ladanyi M. Distinctive neoplasms characterised by specific chromosomal translocations comprise a significant proportion of paediatric renal cell carcinomas. Pathology 2003;35:492-498.

3 de Jong B, Molenaar IM, Leeuw JA, et al. Cytogenetics of a renal adenocarcinoma in a 2-year-old child. Cancer Genet Cytogenet 1986;21:165-169.

4 Clark J, Lu YJ, Sidhar SK, et al. Fusion of splicing factor genes PSF and NonO (p54nrb) to the TFE3 gene in papillary renal cell carcinoma. Oncogene 1997;15: 2233-2239.

5 Argani P, Antonescu CR, Illei PB, et al. Primary renal neoplasms with the ASPL-TFE3 gene fusion of alveolar soft part sarcoma: a distinctive tumor entity previously included among renal cell carcinomas of children and adolescents. Am J Pathol 2001;159:179-192.

6 Argani P, Lui MY, Couturier J, et al. A novel CLTCTFE3 gene fusion in pediatric renal adenocarcinoma with $\mathrm{t}(\mathrm{X} ; 17)(\mathrm{p} 11.2 ; \mathrm{q} 23)$. Oncogene 2003;22:5374-5378.

7 Armah H, Parwani A, Surti U, et al. Xp11.2 translocation renal cell carcinoma occurring during pregnancy with a novel translocation involving chromosome 19: a case report with review of the literature. Diagn Pathol 2009;4:15.

8 Garraway LA, Widlund HR, Rubin MA, et al. Integrative genomic analyses identify MITF as a lineage survival oncogene amplified in malignant melanoma. Nature 2005;436:117-122.
9 Davis IJ, Kim JJ, Ozsolak F, et al. Oncogenic MITF dysregulation in clear cell sarcoma: defining the MiT family of human cancers. Cancer Cell 2006;9: 473-484.

10 Ladanyi M, Lui MY, Antonescu CR, et al. The der(17)t(X;17)(p11;q25) of human alveolar soft part sarcoma fuses the TFE3 transcription factor gene to ASPL, a novel gene at 17q25. Oncogene 2001;20: 48-57.

11 Argani P, Aulmann S, Illei PB, et al. A distinctive subset of PEComas harbors TFE3 gene fusions. Am J Surg Pathol 2010;34:1395-1406.

12 Armah HB, Parwani AV. Renal cell carcinoma in a 33-year-old male with an unusual morphology and an aggressive clinical course: possible Xp11.2 translocation. Pathology 2008;40:306-308.

13 Malouf GG, Camparo P, Molinié V, et al. Transcription factor E3 and transcription factor EB renal cell carcinomas: clinical features, biological behavior and prognostic factors. J Urol 2011;185:24-29.

14 Koie T, Yoneyama T, Hashimoto Y, et al. An aggressive course of Xp11 translocation renal cell carcinoma in a 28-year-old man. Int J Urol 2009;16:333-335.

15 Macher-Goeppinger S, Aulmann S, Wagener N, et al. Decoy receptor 3 is a prognostic factor in renal cell cancer. Neoplasia 2008;10:1049-1056.

16 Macher-Goeppinger S, Aulmann S, Tagscherer KE, et al. Prognostic value of tumor necrosis factor-related apoptosis-inducing ligand (TRAIL) and TRAIL receptors in renal cell cancer. Clin Cancer Res 2009;15: 650-659.

17 Aulmann S, Longerich T, Schirmacher $\mathrm{P}$, et al. Detection of the ASPSCR1-TFE3 gene fusion in paraffin-embedded alveolar soft part sarcomas. Histopathology 2007;50:881-886.

18 Komai Y, Fujiwara M, Fujii Y, et al. Adult xp11 translocation renal cell carcinoma diagnosed by cytogenetics and immunohistochemistry. Clin Cancer Res 2009;15:1170-1176.

19 Argani P, Olgac S, Tickoo SK, et al. Xp11 translocation renal cell carcinoma in adults: expanded clinical, pathologic, and genetic spectrum. Am J Surg Pathol 2007;31:1149-1160.

20 Argani P, Lal P, Hutchinson B, et al. Aberrant nuclear immunoreactivity for TFE3 in neoplasms with TFE3 gene fusions: a sensitive and specific immunohistochemical assay. Am J Surg Pathol 2003;27:750-761.

21 Zhong M, De Angelo P, Osborne L, et al. Dual-color, break-apart FISH assay on paraffin-embedded tissues as an adjunct to diagnosis of Xp11 translocation renal cell carcinoma and alveolar soft part sarcoma. Am J Surg Pathol 2010;34:757-766.

22 Hong S, Oh H, Valera VA, et al. Inactivation of the FLCN tumor suppressor gene induces TFE3 transcriptional activity by increasing its nuclear localization. PLoS ONE 2010;5:e15793.

23 Tsuda M, Davis IJ, Argani P, et al. TFE3 fusions activate MET signaling by transcriptional up-regulation, defining another class of tumors as candidates for therapeutic MET inhibition. Cancer Res 2007;67:919-929.

24 Bagai R, Fan W, Ma PC. ARQ-197, an oral smallmolecule inhibitor of c-Met for the treatment of solid tumors. IDrugs 2010;13:404-414. 